usually occur in spring and autumn. Young growing animals show areas of rapid hair growth more frequently and do not show the same seasonal incidence. No such areas have been noted on depilated guinea pigs.

Hair growth on the rabbit may be artificially modified by agents that induce localized hyperæmia. For example, in animals which have recovered from vaccinia lesions the hyperæmia engendered by the vaccinia pocks persists and a strong growth of hair frequently occurs exactly over the sites of the healed vesicles. This hair appears to be quite normal except that it is surrounded by relatively bare areas on which no vesicle, and therefore no hyperæmia, has occurred. Similar growth takes place after the intracutaneous injection of small doses of diphtheria toxin.

These observations correlate well with the experimental results of Haddow et al. that "by far the greatest density of capillaries occurs in those positions which correspond to the advancing edge of the growing hair-," and that "it is likely that the pigment (the flavin dye) enters growing areas partly because these are the only ones in sufficiently active interchange with the general circulation". From the observations on the rabbit reported here it appears likely that both rapid growth and natural pigmentation of the hair shaft in this animal are correlated with local increased blood supply to the hair follicles.

Lister Institute of Preventive Medicine, C. W. Hale.

Elstree, Herts. April 14.

${ }^{1}$ Haddow, A., Elson, L. A., Roe, E. M. F., Rudall, K. M., and Timmis, G. M., Nature, 155, 379 (1945).

\section{Feeding Twitch Rhizomes as an Alternative to Hay}

TwITCH, or couch, grass (Agropyron repens) is among the common weeds which are difficult to eliminate. It is widespread, and persistent 'cleaning' of the soil seldom eliminates the whole stock; even more serious is the widely dispersed pest in hedge banks and other uncultivated plots. It is not only distributed by air-borne seeds, but it also extends rapidly by the creeping roots or rhizomes.

The roots or rhizomes are palatable and pigs are known to be fond of them. They also proved palatable when fed to domestic rabbits.

The chemical composition of dried roots of twitch showed them to be somewhat similar to meadow hay of good and lower-grade qualities ; the rhizomes contain less fibre and somewhat less protein and mineral matter but, compared with cereal straw, rhizomes appear to be superior in protein and carbohydrate content :

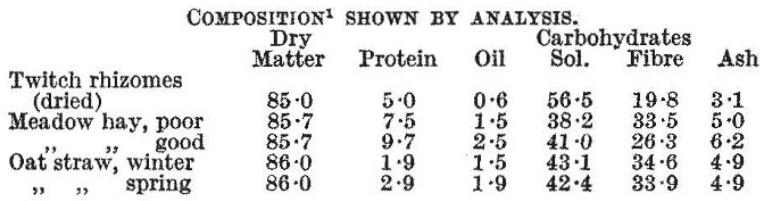

The shortage of hay supplies, following the 1944 drought during the growing season, has accentuated the need for hay substitutes ${ }^{2,3}$.

Several palatability tests proved that rabbits ate the rhizomes more readily than rough grass hay and it was therefore decided to carry out a small feedingtrial.
Feeding Rhizomes. Eighteen resting female rabbits of Beveren type were divided into two similar groups. All but one in each group were yearlings ; the other was approximately three years old. The basal maintenance diet consisted of succulents, greenfood (of variable quality, according to seasonal supply, but similar for both groups) and/or roots, supplemented by meal mash containing minerals and cod liver oil. Water was provided. The control group received rough grass hay, cut from poultry runs, while the other group was given dried twitch rhizomes of common couch or twitch grass.

The hay supply consisted of hard fescue and tall oat grass, cocksfoot, smooth-stalked meadow grass, fiorin, Yorkshire fog and a trace of clover. The species predominance was in that order.

The rhizomes were harrowed out and then forked over and air dried. They were relatively clean in appearance and were stored and fed in this state for the first eighteen weeks of the trial. During the remaining period, freshly dug roots were used; but owing to excessive soil adhering to them they were washed and air dried, although the time of year (Novepnber) precluded complete drying of this supply.

During a preliminary week, it was found that average daily consumption rates were, hay $0.75 \mathrm{oz}$. and rhizomes $1.06 \mathrm{oz}$. Therefore the supply was restricted, averaging $0.7 \mathrm{oz}$. per head per day in each group.

Throughout the period of feeding unwashed and dried rhizomes, this group maintained a slight advantage in live weight over the controls fed on hay. After the change-over to freshly dug rhizomes the twitch group continued to give slightly heavier body weight in all but three weeks in spite of the reduced dry matter intake.

At the conclusion of twenty-five weeks of feeding twitch grass rhizomes as a substitute for hay the average live weight had increased in the hay group by $3.70 \mathrm{oz}$, and in the rhizomes group, $4.91 \mathrm{oz}$.

The condition of the animals was good, although they were moulty at the commencement, and improved as they moulted through. Health was excellent, with one exception in each group. An older one in each group died in the tenth week on twitch, and eighteenth week on hay. The respective postmortem examinations by the veterinary officer revealed nephritis (twitch) but examination for sand was negative ; and abscesses on the spleen and liver (hay). The rest of the stock remained free from symptoms of disease. The coats appeared to be slightly silkier on rhizomes than hay at the end of the seventh week; but after the feeding of freshly dug rhizomes the tendency appeared to be reversed. While there were differences between individuals within groups, the differences between groups were not outstanding, and appeared to depend largely on the stage of the moulting process.

Summary. Air-dried twiteh grass rhizomes, either washed or otherwise, were found to be palatable to domestic rabbits. The rhizomes were less bulky than an equal weight of rough grass hay and were eaten more quickly, and they proved to be a satisfactory substitute for hay when fed in maintenance rations for 175 days.

Harper Adams Agricultural College,

W. KIng Wilson,

$$
\text { Newport, Shropshire. }
$$

${ }^{1}$ Min. Agric. Bull. No. 124 (1942).

${ }^{2}$ Wilson, W. King, Nature, 147, 796 (1941).

${ }^{3}$ Wilson, W. King, Harper Adams Util. Poultry J., 29, 45 (1944). 